\title{
Uma leitura ambivalente sobre a adoção de uma base curricular nacional: para fazer justiça à reflexividade da filosofia da educação*
}

\section{An ambivalent reading about the adoption of a national curricular base: doing justice to the reflexivity of the philosophy of education}

\author{
Vânia Lisa Fischer Cossetin**
}

\begin{abstract}
RESUMO
O presente artigo pretende verificar em que medida a adoção de uma base curricular nacional poderia ser justificada ante a pretensão de qualificar e universalizar a educação brasileira, e em que medida poderia ser preterida por não fazer jus a nossa multifacetada realidade educacional. $\mathrm{O}$ primeiro enfoque chama a atenção para o potencial emancipador e universal da educação em tensionamento com certa perspectiva teórica que acentua as diferenças do humano e privilegia as contingências contextuais. O segundo, problematiza a proposta de formulação de uma base comum curricular, destacando algumas contradições que justificariam sua polêmica e suposta ilegitimidade diante do atual cenário nacional.
\end{abstract}

Palavras-chave: Educação. Universalidade. Base Curricular Nacional.

DOI: $10.1590 / 0104-4060.51175$

* Artigo apresentado em Mesa-redonda sobre a Base Nacional Comum Curricular, no Seminário Ensino Médio: desafios e possibilidades para o processo educativo, promovido pela Universidade Federal de Santa Maria, em julho de 2016.

** Universidade Regional do Noroeste do Estado do Rio Grande do Sul. Ijuí, Rio Grande do Sul, Brasil. Rua do Comércio, nº 3000. Universitário. CEP: 98700-000. E-mail: vania.cossetin@ unijui.edu.br 


\begin{abstract}
The present article aims to verify to what extent the adoption of a national curricular base might be justified in view of the pretension of qualifying and universalizing Brazilian education, and to what extent it might be rejected for not living up to our multifaceted educational reality. The first approach seeks to draw attention to the emancipatory potential and universal of education in tension with a certain theoretical perspective that accentuates the differences of the human being and gives privilege to the contextual contingencies. The second approach problematizes the proposal of elaborating a common curricular base, highlighting some contradictions, which might justify its controversy and alleged illegitimacy when faced with the current national scenario.
\end{abstract}

Keywords: Education. Universality. National Curricular Base.

Antes de iniciar a discussão a respeito do objeto mesmo desse artigo, gostaria de fazer alguns esclarecimentos preliminares atinentes à análise filosófica que orienta a presente leitura e problematização. Em primeiro lugar, parto da premissa de que nenhuma reflexão pode fazer justiça à filosofia e à educação - as referências epistêmicas desses escritos - sem o empenho obstinado em pensar a polaridade e as nuances do objeto em análise, justamente por considerar o pressuposto fundamental de que todo objeto é um objeto complexo. Em segundo lugar, julgo que, apesar do esforço em contemplar a referida complexidade, a construção de um texto dessa ordem se dá em meio a uma certa processualidade e dialeticidade das quais nenhum posicionamento conclusivo unilateralizado pode ser esperado, nem dele derivado prescrições. É nesse sentido que a análise acerca da adoção de uma base curricular nacional será desenvolvida. Uma proposta que sempre se apresentou controversa desde que fora mencionada pela primeira vez na LDB de 1971, mas que acabou ganhando contornos polêmicos com a proposta encaminhada pelo MEC em 2015². Daí em diante as discussões mais dissonantes foram encetadas em redes sociais, sites oficiais, revistas especializadas, discussões acaloradas no interior de instituições de ensino e universidades, desdobrando-se em dois posicionamentos em disputa: um favorável a uma base curricular comum; outro contrário, em proporção notoriamente mais expressiva.

Muito embora o documento supracitado tenha sido o provocador das presentes discussões, não é esta ou aquela proposta que está aqui em questão,

1 Refiro-me, aqui, à proposta, preliminarmente apresentada pelo Ministério de Educação (MEC), de elaboração de uma Base Nacional Comum Curricular (BNCC), baseada na meta 7 do Plano Nacional de Educação (PNE), cujas primeira e segunda versões foram divulgadas em 2015 e 2016 respectivamente (BRASIL, 2016). 
mas, antes, os pressupostos e o significado da construção de uma base curricular comum e a sua implementação nas escolas públicas brasileiras. Nesse sentido, o intuito destes escritos é verificar em que medida a construção e adoção de uma tal base poderia ser compreendida positivamente, inclusive pretendida, se considerado o caráter democrático previsto pela educação republicana brasileira; e em que medida um projeto desse gênero estaria em contradição com a nossa realidade educacional. No primeiro caso, a análise enfoca o aspecto da universalidade da educação ${ }^{2}$ e o papel da escola, nesse contexto, em tensionamento com uma dada perspectiva educacional inclinada a acentuar as diferenças do humano e das suas relações, bem como as idiossincrasias subjetivas e as contingências contextuais. No segundo caso, a intenção volta-se à problematização da tendência intrinsecamente articulada e administrada do sistema avaliativo - embora não necessariamente - que uma base comum pode indicar e a dificuldade de efetivação de uma proposta que, em parte, se apresenta estranha e incoerente frente aos contextos aos quais se aplica.

\section{Por que dizer sim a uma base curricular nacional?}

Inicialmente gostaria de propor uma reflexão à luz do pensamento de Michael Young (2016), a partir de uma interrogação que considero fundamental e sem a qual parece impossível enfrentar o problema em pauta: o que deveria ser ensinado em todas as escolas brasileiras, a todas as crianças e jovens, "independentemente de seus contextos". Logo, do lugar em que vivem, se são ricas ou pobres, se suas famílias são ou não estruturadas, se têm ou não o que comer ou vestir, se são índias, brancas ou afrodescendentes?

Sem dúvida alguma, essa não é uma pergunta cuja resposta possa ser dada prontamente. Ela nos convoca a enfrentar um debate que se estende há décadas a respeito do conjunto de ideais e fundamentos filosóficos que norteiam a educação. Desde a crítica nietzschiana ao sistema de crenças e valores da tradição metafísica, nos deparamos com uma tentativa - obviamente justificada - de romper com modelos educacionais orientados por uma noção de natureza humana, com processos formativos padronizadores e totalizadores, norteados por um ideal previamente fixado e baseados numa ética teleológica da perfectibilidade. No

2 Em que pese a possibilidade de retomarmos o aspecto universal da educação desde a sua gênese moderna, a exemplo de Kant e Condorcet, a discussão aqui encetada orienta-se, sobretudo, pelos escritos de Fernando Savater (2012), o qual, por sua vez, tem tal princípio moderno no horizonte de suas reflexões. 
entanto, o lado oposto dessa moeda, no qual ganham proeminência as noções de contingência, diferença, pluralidade, relativismo, portanto, o entendimento de que não haveriam verdades, mas apenas interpretações, acabou gerando um sentimento de insegurança e desorientação no campo educacional. E mais, a compreensão de que se os valores são constructos humanos que submetem a natureza à razão, para falar com Nietzsche (2009), e de que as relações humanas implicam relações de poder, tal como diagnosticado por Michel Foucault (1979), então toda intervenção pedagógica seria coercitiva e opressora. Isso explicaria porque noções tais como autoridade, tradição, formação e universalidade passaram a ser profundamente questionadas e evitadas, senão banidas dos debates educacionais.

Assim como a radicalidade e a fixação em uma das extremidades desse pêndulo são problemáticas e tendem a produzir consequências indesejadas no contexto educativo escolar, assim também posições polarizadas e maniqueístas, diante de uma base curricular nacional, não poderiam ser profícuas, exceto se nos dispusermos ao diálogo e, se preciso for, fazermos concessões. Sabemos que a disputa teórica e ideológica que subjaz ao debate sobre uma base curricular comum tenciona a necessidade, ou não, de sua implementação e efetivação. Dentre os inúmeros argumentos contrários ${ }^{3}$, aquele que tem se destacado no atual cenário, tanto pelo número de menções em meio às consultas e às manifestações de toda ordem nas instâncias de debate, quanto pela atenção dos críticos, é o que alega que uma base curricular nacional sacrificaria as peculiaridades dos contextos, justamente porque estaria pautada num modelo moderno de pretensões universais.

Segundo a perspectiva aqui defendida, o conceito de universalidade seria justamente o aspecto inegociável da educação e que está implícito na pergunta que inaugura a presente seção. A formação humana conduzida mediante processos administrados de homogeneização, de produção de identidades em série, ou de cerceamento da diversidade, deve ser questionada e tensionada, desde que conjuntamente com a consideração dos fundamentos daquilo que sustenta nosso ideal civilizatório: a escolarização e, por conseguinte, o status que o conhecimento nela assume. A escola é a expressão daquilo que concebemos como indispensável à constituição da subjetividade, da sociedade e da humanidade. Por isso entendemos que todas as crianças precisam passar por ela e nos espantamos caso isso não ocorra. Pais, professores, conselhos tutelares, promotorias, secretarias e coordenadorias de educação, todos são convocados a responder

3 Tais objeções foram identificadas em argumentos e, por vezes, em manifestações inconsistentes expressos numa grande variedade de artigos, pareceres, palestras, blogs de opiniões, programas televisivos, razão pela qual nenhuma referência em especial cabe, aqui, ser mencionada. 
caso isso não ocorra. Consideramos que há, na escola, algo de muito valoroso que toda criança precisa aprender e vivenciar, apesar de suas idiossincrasias individuais ou das peculiaridades dos grupos aos quais pertence.

Considerar a universalidade da educação, nesse sentido, "significa colocar o feito humano - linguístico, racional, artístico... - acima de seus modismos; avaliá-lo em seu conjunto antes de começar a ressaltar suas qualidades locais; e sobretudo não excluir ninguém a priori do processo educacional que o potencializa e o desenvolve" (SAVATER, 2012, p. 143). E isso nós fazemos considerando diversidade, contingência, singularidade, mas também definindo diretrizes, normatizações, coordenando ações, delineando objetivos, conduzindo processos. De modo que o desafio que se impõe diante da necessidade de construção de uma base curricular comum é justamente atender essa polaridade.

\section{Enfrentando o dilema: entre o particular e o universal}

A consideração das diversidades - sejam elas de ordem social, étnica, cultural, econômica ou relativa às próprias individualidades tais como potencialidades, habilidades, limites, aspirações - não se colocam, para pensar com Savater, como o mais particular, mas, ao contrário, como o mais universal. Para ele, aquilo que é próprio do humano em distinção com os outros animais (potencial linguístico e simbólico, disposição racional, consciência da morte) “[...] é aquilo que nos torna semelhantes e que nunca está ausente onde há homens, o que nenhum grupo, cultura ou indivíduo pode reclamar como exclusivamente seu, o que temos em comum" (SAVATER, 2012, p. 148). Todo o resto - ou seja, as expressões culturais, a diversidade das línguas, as crenças, enfim, a diversidade característica da cultura - é justamente a expressão da nossa matriz humana comum. Somente retornando a essa raiz universal compartilhada é que podemos nos aproximar e nos tornar, segundo o autor, "[...] hóspedes uns dos outros, cúmplices de necessidades que conhecemos bem, e não estranhos encerrados na fortaleza inacessível de nossa peculiaridade" (SAVATER, 2012, p. 149).

Savater nos convoca a pensar se o realce daquilo que nos diferencia uns dos outros deve mesmo ser levado tão a sério quando falamos em educação, justamente porque o movimento formativo escolar pretende vínculos, diálogos, articulações, enlaces, integrações, que nos são possíveis quando ressaltamos o que nos aproxima. Ou seja, quando tomamos o humano como a grande esteira sobre a qual nossas diferenças podem ganhar contornos. As peculiaridades culturais, nesse caso, não são ignoradas, muito menos eliminadas. Ocorre, 
porém, que, se consideradas como diferenças simplesmente, elas impedem a intersecção entre os humanos, entre suas culturas, seus modos de existência e expressão. A atenção exclusiva às particularidades tende a gerar mais diferença e, com isso, mais exclusão, exatamente porque elas tendem a acentuar os limites e as fronteiras com o outro.

Por isso, mesmo reconhecendo a cultura alheia, do ponto de vista dos fins da educação, consequentemente, das intenções formativas e das intervenções pedagógicas, somos sempre convocados a um compromisso ético para com a geração recém-chegada, que nos impede de deixá-la tal como está. Dito de outro modo: crianças e jovens não poderiam ser encontradas ao fim do processo do mesmo modo como chegaram a nós. Se nos negarmos a fazer esse tensionamento, supostamente por acreditarmos que suas idiossincrasias subjetivas e culturais devem ser preservadas por não haver um lugar minimamente privilegiado do ponto de vista da sociabilidade possível e, sobretudo, do conhecimento, então a escola deixa de cumprir com aquilo que parecia ser o seu objetivo mais fundamental: permitir que os sujeitos transcendam seu enclausuramento subjetivo e o caráter necessário e fatídico de seus contextos. Mas se concebemos, com Young, que "o respeito pelos valores culturais de uma comunidade" não pode ser confundido "com a verdade das explicações oferecidas pelas disciplinas escolares” (2016, p. 29), então assumimos uma escola cujo compromisso inalienável é oferecer um certo tipo de conhecimento que os alunos não conseguem obter por sua própria experiência.

Em qualquer discussão sobre currículo, a distinção mais básica é entre o conhecimento escolar, ou curricular, e o conhecimento do dia a dia, ou da experiência que os alunos trazem para a escola. Não se trata de que um seja "bom" e o outro, "ruim". É que eles têm estruturas diferentes e finalidades diferentes. O conhecimento curricular - ou disciplinar - é independente do contexto, diferentemente do conhecimento baseado na experiência que os alunos trazem para a escola, que está diretamente ligado aos contextos nos quais as pessoas vivem e dentro dos quais é adquirido (YOUNG, 2016, p. 34).

As singularidades individuais e comunitárias devem ser reconhecidas. Ocorre, porém, que se tomadas como princípios norteadores da educação, o processo de escolarização precisa abandonar uma tarefa que lhe é muito cara: minimizar ou compensar as diferenças que crianças e jovens - inclusive, nós mesmos - não escolhem ter e que dizem respeito aos aspectos acidentais das 
suas existências. Em vista disso, é que a universalidade implícita na adoção de uma base curricular comum acena para a possibilidade de garantir a todos que ingressam na escola o acesso aos mesmos conhecimentos. Uma forma de dar-lhes condições para que, cedo ou tarde, possam tomar consciência de seus direitos e das condições de defendê-los, consequentemente, de se encorajarem a planejar as suas vidas e realizar seus projetos futuros, sobretudo diante dos mesmos desafios a todos impostos pela sociedade contemporânea. Em suma: um meio de amenizar o descompasso que surge como ponto de partida entre os sujeitos e que os impedem de aspirarem outras situações vivenciais para além de seus contextos de origem.

Se isso faz algum sentido, então a organização curricular precisa ser pensada de modo a dar conta de saberes que possibilitem tal empresa. Inclusive reconhecendo que há algo a ser ensinado que, segundo Savater, "[...] não começa com cada um de nós e que há de sobreviver a nós" (2012, p. 43). Em outras palavras, aquilo que de valoroso fora produzido pela humanidade ao longo de seu percurso e que cada nova geração tem o direito de conhecer e a geração que a antecede, o compromisso de ensinar. E é justamente "[...] a defesa de um currículo centrado no conhecimento", conforme Young, o que pode apresentar-se "coerente com uma política de justiça social e maior igualdade [...]" (2016, p. 22). Isso é importante de ser considerado, pois indica o caráter político da construção de uma base curricular nacional, sobretudo o aspecto democrático que caracteriza a escola pública. Nesse caso específico: para que não sejam reféns do acaso, o direito de cada criança de ter acesso ao melhor em termos de conhecimento em qualquer âmbito do país. Mas o que, afinal, deveria ser ensinado a todas as crianças durante a Educação Básica?

Diante dessa pergunta, uma suspeita se precipita, antes mesmo que qualquer resposta possa ser elaborada: parece faltar-nos uma ideia consistente do que é e de como deve ser a Educação Básica no Brasil. Apesar de as políticas públicas conceberem e visarem a Educação Básica como uma unidade, quando chegam na escolar, surgem na forma de programas que mobilizam as etapas e não a sua totalidade. Os projetos, as iniciativas, os estudos, voltam-se à Educação Infantil, aos Anos Iniciais, aos Anos Finais e ao Ensino Médio, todos separadamente. E o que resulta desse longo, fragmentado e, por vezes, contraditório processo formativo? Frequentemente uma Educação Básica esclerosada. Na maioria das vezes - principalmente se a escola não atende toda a etapa de escolarização -, o educador do Ensino Médio não faz a mínima ideia de como foi o percurso formativo dos seus atuais alunos na Educação Infantil. Os professores dos Anos Iniciais cumprem a referida etapa e passam a responsabilidade para a etapa seguinte, também sem ter muita clareza de como o processo se desdobra ulteriormente no Ensino Médio. O aluno passa de etapa em etapa, por dezenas 
de professores, de escolas, de gestores, de projetos, que dificilmente apresentam alguma unidade ao longo do processo. Arriscaria supor, que nunca chegamos a ter, efetivamente, uma Educação Básica no Brasil, é sempre preparatório para uma nova etapa, do Fundamental para o Médio, do Médio para o Ensino Superior ou para o mundo do trabalho. Ainda que esforços legais e algumas experiências pontuais tenham sido empreendidas, para faltar uma unidade mínima que garanta também o mínimo: possibilitar que o sujeito compreenda o mundo, a si mesmo neste mundo e, nele, o seu papel. Se um objetivo tão elementar fica devendo em efetividade diante de tamanho fracionamento e incomunicabilidade no interior da mesma escola, o que não devemos esperar entre elas? E como definir o que nelas deve ser ensinado sem termos clareza acerca dos objetivos formativos que a orientam?

Uma forma de tentarmos delinear uma unidade possível para a Educação Básica é justamente nos desafiarmos a responder ao menos duas perguntas: como aspiramos encontrar a criança que hoje ingressa na Educação Infantil e que, supostamente, dará por encerrado seu percurso de escolarização ao término do Ensino Médio? E que currículo poderia ser considerado para fins de aproximação de tal projeção?

Tão sintonizadas quanto deveriam estar as etapas da Educação Básica entre si, também deveria estar o planejamento de uma base curricular nacional com relação ao projeto da Educação Básica, por conseguinte com aquilo que consideramos mais valoroso na formação do humano e que está sempre balizado - ainda que não definitivamente - por um dado ideal, um modelo de excelência, sem o qual nenhum processo formativo se sustenta. Caso essa questão não seja levada a sério e debatida à exaustão resta-nos admitir que qualquer coisa pode ser ensinada, consequentemente, que qualquer um pode fazê-lo, de modo que não estranharíamos, por exemplo, os pais que retiram seus filhos da escola para que eles mesmos ou outros os eduquem. Se a considerarmos, porém, a pergunta que segue não poderia ser outra: o que deve ser ensinado?

A proposição de Michael Young é a de que haveria "[...] um conhecimento 'melhor' em qualquer área, que poderia ou deveria embasar o currículo escolar" (2016, p. 21). E, como já destacado, um conhecimento pensado a partir de significados "independentes de contextos" (2016, p. 29). Senão, inversamente, deveríamos considerar como adequada uma escolarização que elege o "seu melhor" a partir de situações circunstanciais. Ou seja, a definição do que seja o bom, o bem, o justo, ficaria à mercê de um grupo ensimesmado, que olhando apenas para si acredita poder definir o que é melhor para os seus. Ademais, por tratar-se de crianças e jovens, devemos antever que os sujeitos implicados não se associaram consciente e voluntariamente ao grupo ao qual pertencem, sobretudo porque a "a autoridade de um grupo", conforme Hannah Arendt, “[...] é sempre 
consideravelmente mais forte e tirânica do que a mais severa autoridade de um indivíduo isolado" (2014, p. 230). Na pior das hipóteses, o foco pode se voltar para o indivíduo, o que não minimiza o problema, pois tende a resultar numa educação meramente pulverizada, adaptada às necessidades idiossincráticas.

É difícil sabermos se aquilo que definimos como sendo o melhor para a educação, ou mesmo com relação ao conhecimento, sem nos dispormos a uma discussão honesta, pública e guiada por princípios que transcendam aqueles que nos impomos. Pois é evidente que qualquer regra se torna facilmente cumprida quando nós mesmos as estipulamos, porque o fazemos na medida de nossa possibilidade ou intenção. Para não incorrermos nisso, convém lembrar, com Savater, que

Não há educação se não há verdade a ser transmitida, se tudo é mais ou menos verdade, se cada um tem sua verdade igualmente respeitável e não se pode decidir racionalmente entre tanta diversidade [...]. As verdades são frágeis, revisáveis, sujeitas a controvérsia e, afinal, perecíveis. Nem por isso, no entanto, deixam de ser verdades, isto é, mais sólidas, justificadas e úteis do que outras [...] (2012, p. 126).

No fundo parece que temos certa dificuldade - em especial a partir de algumas perspectivas das Ciências Humanas - de lidar com categorias tais como verdade, resultados, avaliação, regulação, normatividade, autoridade, universalidade e, em alguns casos, até mesmo com conhecimento. Ignoradas tais categorias precisaríamos admitir que nada de confiável ou verdadeiro (embora não absoluto) pode ser considerado, logo, que qualquer coisa pode ser ensinada nas escolas e por qualquer um. Se flexibilidade e relativismo são assumidos como princípios norteadores à configuração de currículos, poderíamos, sem prejuízo, abandonar as decisões fundamentais da esfera formativa ao mercado, aos pais, a cada professor individualmente ou nas mãos dos próprios alunos.

Todavia, educação se faz a partir de diretrizes, de fins, de estratégias. O que não implica em instrumentalizá-la ou cooptá-la com vistas a alguma funcionalidade pré-definida, mas de que o conhecimento precisaria assumir a centralidade do processo educacional, tanto em termos mais objetivos, ou seja, conceituais e conteudísticos, quanto em termos mais abrangentes, como é o caso do aspecto formativo que a orienta. Apesar da necessidade de envolvimento dos mesmos sujeitos em ambas as instâncias e processos, em parte, quando nos referimos às diretrizes, a tarefa recairia sobre os especialistas e, quando nos referimos a estratégias pedagógicas, sobre gestores e professores. Nas duas esferas, as ques- 
tões relativas ao conhecimento, à verdade e à razoabilidade estão implicadas e naturalmente se multiplicam nas inúmeras vozes que as representam, cada qual, porém, reivindicando para si o saber acerca do que seja mais adequado ensinar. A dificuldade é que, assim, a tendência é cairmos na armadilha relativista que se cada um tem uma verdade, verdade mesmo não há. Harmonizar compreensões tão dissonantes a respeito do que cada envolvido pensa sobre educação seria o grande desafio. As formações e motivações são muito variadas e dissonantes e incidem diretamente sobre as compreensões e as posições dos sujeitos. Do ponto de vista das experiências, o que falta a um parece sobrar ao outro. Assim, tão arriscado quanto abandonar os rumos da educação exclusivamente nas mãos de especialistas, que há décadas não pisam em escolas (se é que algum dia o fizeram), é abandoná-los nas mãos de professores cuja precariedade das formações e variedade de interesses - que vão da reserva de emprego, da possibilidade de atuação nas instituições, da distribuição de tempos escolares, a questões ideológicas - também deixam dúvida se essa é a melhor das opções.

\section{A recepção das políticas educacionais}

A escola pública brasileira está baseada nos princípios da universalidade, da laicidade e da publicidade, portanto, expressa aquilo que desde a modernidade surgiu como o perfil da escola republicana. Mas por que, então, a consideração de uma base curricular comum causa tanto desconforto? Esse sentimento pode ter suas raízes fincadas num passado cujos efeitos ainda reverberam no modo de ser político da sociedade brasileira. Nossa tradição política, "[...] pouco afeita a valores democráticos e, em largos períodos, explicitamente ditatorial" (FENSTERSEIFER, 2013, p. 124), teria nos conduzido a duas situações em oposição: ou para um alijamento do potencial protagonista e de empoderamento docente, cuja responsabilidade reflexiva e decisória é transferida para terceiros, numa espécie de desejo de "minoridade" para falar com Kant; ou para uma aversão radical a diretrizes, orientações, normatizações, regulações, leis, vindas do Estado, ainda que elas impliquem na possiblidade de participação no processo de sua construção e a tomada de consciência dos sujeitos nela implicados. Associamos, portanto, “[...] qualquer política para um currículo nacional comum com o período antidemocrático da ditadura militar, e não com o poder potencialmente emancipatório do conhecimento" (YOUNG, 2016, p. 30).

Dessa forma, a dificuldade de recepção, reflexão e efetivação das políticas públicas educacionais estaria, em parte, justificada pela nossa própria história. 
Tomada a consciência deste determinante histórico, o que conferiria aos professores de escolas públicas? No mínimo, ler os documentos atentamente, inteirar-se de seu conteúdo, posicionar-se diante deles, dispor-se à sua reflexão, antes do seu abandono ou crítica. É impossível ser, efetiva e coerentemente, professor de escola pública sem conhecer os fundamentos que a regem. Assim como as políticas educacionais são propositivas, marcam uma linha teórica, definem-se por recortes epistêmicos, também os professores, quando as aceitam ou rejeitam, estão - ou deveriam estar - orientados por uma determinada compreensão sobre a educação, sobre o conhecimento, sobre o currículo. Compreensões que precisam ser justificadas, pois não podem apresentar-se como públicas, quando o seu teor é visivelmente privado/subjetivo. As intervenções pedagógicas e as escolhas que as sustentam frustram qualquer neutralidade no campo da educação, uma vez que o educador, enquanto "[...] escolhe, verifica, pressupõe, convence, elogia, descarta [...] tenta favorecer um tipo de homem em face dos outros, um modelo de cidadania, de disposição para o trabalho, de maturidade psicológica e até de saúde, que não é o único possível, mas que se considera preferível aos demais" (SAVATER, 2012, p. 141). Escolhas e posições que convocam a um determinado compromisso público - mas jamais irrefletido - com o ideário subjacente às políticas educacionais que sustentam o projeto da escola pública. Exemplo disso seria, diante de uma educação que prevê um ensino pautado nos preceitos da laicidade, o professor colocar-se numa postura doutrinária e proselitista, em defesa fanática de uma determinada religião.

O que está em jogo com a construção de uma base curricular nacional é que os professores de escola pública não têm responsabilidade apenas com o cumprimento formal internamente exigido pelo domínio de conhecimentos do componente que ministra, mas um comprometimento com um projeto de sociedade e de humanidade que, por isso, não pode ser reduzido a um projeto de partido político, nem deste ou daquele governo, tampouco de um indivíduo ou grupo. Haveria, portanto, uma espécie de contrato definido a priori entre o professor e a escola pública. O que não implica uma postura meramente receptiva ou mesmo heterônoma de tudo o que vem determinado como proposta, projeto ou lei, visto que o professor deve ser muito mais que um tarefeiro executor técnico de programas, mas um pensador da área de seu domínio, de si e de sua função. Uma postura consequente a isso lhe exigiria, como já dito, a disposição para a leitura e a compreensão dos princípios reguladores dessa esfera.

Se a educação universal preconizada pela escola pública acena para a consideração de um projeto de sociedade e humanidade, posto de antemão diante de toda empreita pedagógica - ainda que provisoriamente, visto a necessidade de sua avaliação e recondução constantes -, então a pergunta pela relevância de uma base curricular nacional deve naturalmente ser feita. $\mathrm{O}$ que na sequên- 
cia tentarei esboçar é que tal discussão não poderia avançar sob o domínio de um enfoque unilateral, que apenas salienta o lado profícuo e necessário de construção de uma base curricular comum, mas também pela exigência de um posicionamento crítico e propositivo diante dos obstáculos e desconfianças relativas à sua efetivação.

\section{Por que dizer não a uma base curricular nacional?}

Nos debates e discussões a respeito da possibilidade de implantação de uma base curricular comum, as críticas têm ganhado proeminência ${ }^{4}$. Dentre elas, duas considero dignas de atenção e reflexão: a perspectiva reducionista a que ela se resume, caso sua finalidade seja a preparação para um determinado sistema avaliativo; e, no caso brasileiro, o escamoteamento das condições ideais para a sua efetivação.

Relativamente ao primeiro ponto, cabe destacar um elemento da crítica que considero altamente relevante. Valho-me da expressão adorniana de sociedade administrada. Ao cunhar a expressão, no texto Teoria da Semicultura (ADORNO, 1996), o filósofo da Escola de Frankfurt referia-se à educação reduzida ao aspecto pragmático, cuja principal finalidade é formar sujeitos para a resolução de tarefas cotidianas, às necessidades do trabalho, da indústria, do mercado. Seria nesse objetivo geral tácito que encontramos um dos principais engodos da implementação de uma base curricular nacional. Seu grande problema encontrar-se-ia nas suas intenções subjacentes e que levariam preocupações de ordem pedagógicas formativas a serem preteridas em nome de interesses alheios à educação. No segundo ponto, são discutidas as incongruências de um projeto que se precipita diante das condições mínimas - por isso, sequer ideais - para a sua concretização, num evidente descompasso entre aquilo que tem sido aclamado como urgente e necessário, que é a valorização e formação de professores, e a tão aspirada qualidade do ensino.

4 Ainda que a análise sobre o desconforto diante da adoção de uma base curricular comum possa ser realizada genericamente, a presente seção está considerando a proposta apresentada pelo MEC, em 2015, e numa segunda versão em 2016, uma vez que ela passou a configurar-se numa possibilidade concreta de efetivação no cenário nacional. Dentre as principais críticas expressas em artigos e debates públicos a respeito, publicados nos mais variados veículos midiáticos, destaco as seguintes: a confusão que o documento apresenta entre conteúdos e objetivos de aprendizagem; o fato de ele definir tais conteúdos/objetivos como uma listagem incoerente internamente ao próprio documento e em dissonância com as condições reais de sua efetivação; a perspectiva reducionista e de uma proposta pensada com fins de preparação para um determinado sistema avaliativo. 


\section{Uma formação administrada}

Um dos problemas relativos à formulação de uma base nacional comum está no risco de que direitos de aprendizagem e aspectos formativos mais gerais sejam reduzidos a uma listagem de conteúdos ${ }^{5}$. Em que pese sua reconhecida importância, conteúdos não são fins, mas cumprem uma função instrumental para que objetivos sejam atingidos. Assim, não poderiam resultar em uma formulação meramente pragmática. Seria ingenuidade, para pensar com Savater, formar ou educar precedendo dos conteúdos (2012, p. 46), todavia, "a arte de ensinar aprender consiste em formar fábricas e não armazéns" (2012, p. 49). Os estudantes não são meros receptáculos, dentro dos quais são colocadas informações selecionadas quantitativamente cuja finalidade é atender demandas externas à escola, tais como o preenchimento de vagas no mercado de trabalho ou adaptar-se ao fenômeno tecnológico informacional, como se as escolas, conforme contundentemente denunciado por Masschelein e Simons (2015), estivessem a serviço da sociedade. Ao reduzir a complexa formação do humano ao aspecto instrumental e administrado do conhecimento, a educação escolar cria margens para que se instale uma lógica perversa dentro da qual a experiência e a atividade humanas passam a ser organizadas de forma a produzirem resultados que possam ser medidos. Não se trata de que os modos de coordenar, planejar e gestar a educação com vistas à universalidade devam ser inibidos. Esta, inclusive, seria uma tarefa da qual políticas públicas e escolas não poderiam prescindir. Ocorre que, em educação, a relação entre causas e efeitos não são exatamente previsíveis e mensuráveis, tampouco a função do professor pode ser reduzida a um mediador instrumental que concebe a escola como instituição a serviço da sociedade ou que compactua com o seu recrutamento para um ranking de desempenho ao qual estranhamente é forçada a participar.

Assim, por mais que o projeto de uma base curricular nacional possa contribuir para a qualificação da educação pública e, por conseguinte, ampliar as conquistas democráticas da sociedade, jamais o poderá fazer às custas da

5 No caso da BNCC 2015/2016, muitos desses conteúdos - senão sua maioria - são tomados por objetivos. Para exemplificar destaco dois objetivos de áreas diferentes. No caso da Física lemos: "Descrever características de feixes de luz policromáticos, como de velhas lanternas de pilha, monocromáticos, como de lâmpadas de sódio, e coerentes, como o laser, que pode ser utilizado no transporte de informações, analogamente às ondas de rádio". E no caso da Filosofia: "Refletir sobre os processos de formação e circulação de opinião - midiáticos, propagandísticos, artísticos, educacionais ou religiosos -, com atenção às suas injunções políticas". Note-se que, em ambos os casos, o caráter mais universal e formativo fundamental que compreende os objetivos foi ignorado. Travestidos de conteúdos, tornaram-se meios e não fins. 
instrumentalização da escola. Mas também não o poderá comprometendo a diversidade e a pluralidade em nome da homogeneização, tampouco ignorando a capacidade autônoma dos sujeitos nela envolvidos, fruto histórico de uma concepção segunda a qual o professor é antes um trabalhador da educação, um executor de projetos alheios, do que um pensador. Que as políticas educacionais, os projetos pedagógicos das escolas, a organização curricular, inclusive as opções metodológicas, devem estar afinadas entre si, de modo a permitir seu acompanhamento, avaliação e responsabilização quanto aos seus gestores e executores, isto é inquestionável. Contudo, é preciso estar atento para que projetos políticos educacionais, particularmente no caso da formulação de uma base curricular comum, não se reduzam a um simples mecanismo de controle e/ou substituam a perspectiva formativa, que deveria estar no horizonte do processo educativo, a meras prescrições pela ênfase em conteúdos mínimos - cuja tendência, na prática, é tornar-se o máximo a ser considerado.

\section{$O$ instrumento de controle: o sistema avaliativo nacional}

A avaliação dos processos é, indubitavelmente, uma etapa importantíssima para a qualificação da educação básica. Se planejada coerentemente, considerando as fragilidades formativas de muitos profissionais que nela atuam, a precariedade estrutural de boa parte das escolas e também as diferenças derivadas da facilidade ou debilidade de acesso aos bens culturais entre os sujeitos envolvidos, o seu valor revela-se inquestionável, sobretudo por garantir certa organicidade e complementariedade ao longo do processo formativo, bem como o compromisso público e coletivo que ele implica.

O problema é quando o modo de garantir essa articulação corre o risco de se dar, não pela oferta de condições formativas, de trabalho e estruturais mínimas para aqueles que se ocupam com a educação, consequentemente, pela pressuposição do convencimento e adesão dos envolvidos, mas de um mecanismo de controle cujo intuito é justamente fazer todo o enlace dessa educação administrada: o sistema de avaliação. Sistema que raramente submete à avaliação os seus próprios instrumentos e que, apesar de legítimo e eficaz de diagnosticar a realidade educacional, revela-se pouco eficaz na superação dos seus problemas.

Um dos resultados possivelmente obtidos com a implementação de uma base curricular comum seria o aumento do desempenho e dos índices de aprovação nas avaliações externas. Parece não haver dúvidas de que os currículos seriam pensados a fim de cumprir tal finalidade. Um currículo nacional seria 
perfeito para isso: na radicalidade, uma escola preparatória, partícipe de uma lógica circular, cujo valor passaria a ser medido pelo êxito nos resultados. Estaríamos, assim, na iminência de uma educação meramente servil e em contradição com as amplas discussões - que inclusive orientaram a formulação de boa parte dos documentos oficiais para a educação - a respeito da importância de uma educação escolar formativa e não simplesmente instrutiva, além de sermos levados a compactuar com a ideia controversa de que o aumento da nota corresponde à qualidade do ensino e da aprendizagem.

Um projeto, assim, estrategicamente pensado, induziria a ações coordenadas entre todo o sistema de ensino. O que não é de todo reprovável, desde que o fosse pela harmonização das intenções e pela consideração da fragilidade das condições formativas e estruturais que historicamente têm assolado a realidade educacional brasileira ${ }^{6}$.

\section{Condições de possibilidade para a efetivação de uma base curricular nacional}

No Brasil, as desconfianças a respeito das condições de possibilidade de efetivação de uma base curricular nacional justificam-se, precipuamente, pela conjuntura que nos é muito familiar relativa ao quadro geral docente: debilidade da formação superior, inconclusão dos cursos de graduação, ausência de formação na área de atuação, fragilidade e pouca adesão às formações continuadas, déficit salarial, entre outros. Sendo assim, por que as ações concernentes à tentativa de qualificar a educação não partem da formação e valorização de professores?

Arrisco afirmar que aquilo que se faz de bom em educação, faz-se com bons professores. A recíproca, contudo, não é necessariamente verdadeira. Pois, em caso de malogro, a formação deficitária e, em geral, a desassistência por parte do poder público são corresponsáveis. A desconsideração dessa incongruência só mascara o problema, posto que, num contexto de emergência, as tentativas de solução tendem a evocar os resultados para justificar as ações quando deveriam atentar para a sua gênese. Esta é uma das grandes dificuldades que obstaculiza o movimento de instauração de uma base curricular nacional. É como reduzir a maioridade penal ou instituir a pena de morte para acabar com o crime: a causa da violência ou da criminalidade permanece incólume.

6 Além disso, legitimado o sistema avaliativo, seguramente uma racionalização da produção de materiais didáticos deve ser esperada e, com ele, uma disputa ainda mais atroz entre as editoras. 
A adoção de uma base curricular comum, portanto, indicaria que as condições para a sua realização já estariam adequadas para aquilo que ela se propõe. O que não é o caso, sequer uma novidade. No Brasil, as leis educacionais costumam ser aprovadas antes mesmo que o caminho para sua acolhida esteja preparado. Em que pese a sua necessidade e urgência, desse modo, a lei passa a ser estranhamente imposta aos contextos aos quais se aplica. E por não derivar organicamente deles, corre o risco de ser abandonada ou demorar demasiadamente para ser incorporada, a exemplo do que aconteceu com a lei da inclusão ${ }^{7}$.

No caso da efetivação de uma base curricular nacional, talvez não vejamos uma situação diferente. Como já é de se esperar, até que o equilíbrio entre as exigências e as condições se estabeleça, vigorarão os arranjos, os boicotes, as fraudes. Ou talvez não, porque, diante da precariedade das condições de alguns contextos, é possível que a honestidade do tipo "não faço porque não sei" ou "não faço porque não tenho condições para isso" seja uma justificativa para induzir providências governamentais a posteriori a fim de que se cumpra minimamente o proposto.

Certo é que, a despeito de qual ou de como um projeto com esse conteúdo venha a consolidar, a possibilidade de discuti-lo sob aspectos epistemológicos, políticos, pedagógicos, ideológicos, éticos, já é profícua, sobretudo devido ao posicionamento que somos intimados a assumir em meio a um campo nada neutro, mas de muitas disputas. Aliás, nenhum documento sobre currículo trata-se de um mero documento técnico. Será sempre fruto de um determinado posicionamento pedagógico, formativo e político, razão pela qual necessita ser pensado também, principalmente, a partir de diretrizes ao invés de restringir-se apenas a instruções de conteúdo. Em boa medida, qualquer perfil que uma base curricular comum venha a assumir, ela sempre se revelará controversa: se for demasiadamente genérica ou se, inversamente, for deixada à mercê de cada sistema de ensino, nenhuma base comum pode ser derivada; se for demasiadamente objetiva corre $\mathrm{o}$ risco de ser reducionista e inflexível para dar conta das diversidades contextuais.

Assim, efetivando-se ou não, esta ou aquela base, provavelmente tais reflexões nos conduzirão ao menos a dois movimentos importantes diante dos desafios da educação brasileira: à ampliação de nossa compreensão a respeito do lugar e do sentido da escola pública e à consciência sobre o que concebemos por educação básica, precisamente sobre aquilo que, nela, não podemos negociar com relação à formação de nossas crianças e jovens.

7 Professores, alunos, funcionários, todos foram surpreendidos pela lei da inclusão. Há 20 anos, desde a LDB de 1996, e quase 10 anos, desde a Política Nacional de Educação Especial na Perspectiva da Educação Inclusiva, de 2007, a educação especial está prevista nas escolas e o sistema ainda não foi adaptado. 


\section{REFERÊNCIAS}

ADORNO, T. W. Teoria da semicultura. Tradução de Newton Ramos de Oliveira com colaboração de Bruno Pucci e Cláudia Moura Abreu. Educação e Sociedade, ano XVII, n. 56, p. 24-56, dez. 1996.

ARENDT, H. Entre o passado e o futuro. Tradução Mauro W. Barbosa. 7. ed. São Paulo: Editora Perspectiva, 2014.

BRASIL. Ministério da Educação. Lei nº 9.394/96. Lei de Diretrizes e Bases da Educação Nacional. Secretaria de Educação Básica, Brasília. Disponível em: < http://www.planalto. gov.br/ccivil_03/Leis/L9394.htm>. Acesso em: 09 jul. 2016.

BRASIL. Lei n ${ }^{\circ}$ 13.005, de 25 de junho de 2014. Plano Nacional de Educação 2014-2024. Brasília. Disponível em: <http://www.planalto.gov.br/ccivil_03/_Ato2011-2014/2014/ Lei/L13005.htm>. Acesso em: 02 jul. 2016.

BRASIL. Ministério da Educação. Base Nacional Comum Curricular $-2^{a}$ versão. Brasília. Disponível em: <http://basenacionalcomum.mec.gov.br/\#/site/inicio>. Acesso em: 02 jul. 2016.

FENSTERSEIFER, P. E. Função da escola pública. In: SANTIAGO, A. R. F.; FEIL, I. T. S.; ALLEBRANDT, L. I. (Org.). O curso de pedagogia da Unijuí: 55 anos. Ijuí: Editora Unijuí, 2013.

FOUCAULT, M. Microfísica do poder. Tradução: Roberto Machado. 20. ed. Rio de Janeiro: Edições Graal, 1979.

MASSCHELEIN, J.; SIMONS, M. Em defesa da escola: uma questão pública. Tradução: Cristina Antunes. 2. ed. Belo Horizonte: Autêntica Editora, 2015.

NIETZSCHE, F. W. Genealogia da moral. Tradução: Paulo César Souza. São Paulo: Companhia das Letras, 2009.

SAVATER, F. O valor do educar. Tradução: Monica Stahel. 2. ed. São Paulo: Editora Planeta, 2012.

YOUNG, M. Por que o conhecimento é importante para as escolas do século XXI? Tradução: Tessa Bueno. Cadernos de Pesquisa, v. 46, n. 159, 2016.

Texto recebido em 14 de março de 2017. Texto aprovado em 14 de abril de 2017. 
